\title{
Pituitary gene expression differs in D-galactose-induced cell senescence and steroid-induced prolactinomas
}

\author{
TIEHUI ZHANG ${ }^{1-3}$, BINHAI ZHAO ${ }^{3}$, JIA LI $^{3}$, CHUNLEI ZHANG $^{3}$, HONGZHI LI $^{3}$, \\ JIANG WU $^{1}$, SHIMING ZHANG ${ }^{1}$ and GUOZHEN HUI ${ }^{1}$ \\ ${ }^{1}$ Department of Neurosurgery, The First Affiliated Hospital of Soochow University, Suzhou, Jiangsu 215006; \\ ${ }^{2}$ Department of Neurosurgery, Traditional Chinese Medical Hospital of Zhejiang Province, \\ Hangzhou, Zhejiang 310006; ${ }^{3}$ Heilongjiang Key Laboratory of Anti-Fibrosis Biotherapy, \\ Mudanjiang Medical University, Mudanjiang, Heilongjiang 157011, P.R. China
}

Received March 4, 2014; Accepted November 19, 2014

DOI: $10.3892 / \mathrm{mmr} .2014 .3062$

\begin{abstract}
In general, pituitary tumors are benign with low mitotic activity. Premature senescence has been considered to be a significant mechanism underlying this uniquely benign pituitary tumor. The present study aims to compare the expression of the associated proteins involved in premature senescence pathways among normal, aging and pituitary adenoma cells. We successfully induced the aging pituitary using continuous D-galactose (D-gal) injection as well as a prolactin-secreting pituitary tumor via diethylstilbestrol implants. Compared with normal pituitary cells, the aging pituitary tissues revealed increased expression of IL-6, C/EBP $\beta$, p53, p21 and p16 and decreased expression of pituitary tumor transforming gene. In contrast, the expression of IL-6, p21 and p16 was decreased in pituitary tumor cells compared with normal pituitary tissues. Taken together, multiple pathways including IL-6/C/EBP $\beta$, p53/p21 and p16 were activated in aging pituitary cells in response to D-gal treatment. However, all these pathways were immune to pituitary tumors treated by chronic estrogen. The findings and the involvement of cytokines in a highly prevalent natural disease model (pituitary adenomas) indicate a potential use of this pathway as a target for effective therapy for tumor silencing and prevention of adenoma progression towards malignancy.
\end{abstract}

Correspondence to: Mr. Shiming Zhang or Mr. Guozhen Hui, Department of Neurosurgery, The First Affiliated Hospital of Soochow University, 188 Shizi Street, Suzhou, Jiangsu 215006, P.R. China

E-mail: shim_zhang@126.com

E-mail: guozhhui@126.com

Key words: pituitary tumors, aging pituitary, premature senescence, IL-6, p53, p21

\section{Introduction}

Pituitary tumors are derived from highly differentiated pituitary cell subtypes which are somatotrophs secreting hormones, lactotrophs expressing prolactin (PRL), thyrothrophs secreting thyrotropin and corticotrophs secreting adrenocorticotropin (1). PRL-producing adenomas are the most common of these.

Pituitary-type adenomas may cause significant local compression due to the mass effect and inappropriate secretion of pituitary hormones $(2,3)$. They are commonly encountered and are invariably benign. Stable or indolent growth has been observed in pituitary adenomas (4). Pituitary adenomas rarely progress to malignant carcinoma $(5,6)$. Low mitotic activity has been observed in aggressive pituitary adenomas in comparison with tumors arising from more rapidly replicating tissues (7). A new finding is that pituitary cells undergo premature senescence, enabling escape from the proliferative pressure of oncogenes, hormones and transformation factors (8). Cellular senescence is broadly considered as the causative mechanism underlying the benign biological behavior of pituitary tumors. Cellular senescence is a key biological progress which controls cell proliferation and may play an essential role in tumor suppression (8). Age-related telomere shortening may cause cell senescence, also known cellular aging or replicate aging (9-11). By contrast, premature senescence occurring prior to telomere shortening is caused by oxidative stress, DNA damage, aneuploidy, chromosomal instability and oncogene activation (12). It is reported that both non-tumorous and tumorous pituitary cells are prone to senescence $(13,14)$. Premature cellular senescence is considered to be the essential mechanism underlying the ability of pituitary cells to escape aggressive proliferation and malignant transformation $(14,15)$.

Pituitary cellular senescence is characterized by increased senescence-associated $\beta$-galactosidase (SA- $\beta$-Gal) activity, chromosome condensation, DNA damage and upregulation of cell cycle progression inhibitors including p19, p16 and p21 (16). The mechanisms underlying pituitary senescence are not entirely clear. Multiple cellular pathways and cytokines may be involved in triggering pituitary cell senescence. 
One mechanism may be the activation of DNA damage and $\mathrm{p} 53 / \mathrm{p} 21$ senescence induced by the securin properties of the pituitary tumor transforming gene (PTTG) (17). The pathway of $\mathrm{p} 16 / \mathrm{Rb}$ or IL-6/C/EBP $\beta$ mediates the oncogene-induced senescence $(18,19)$. Autocrine IL-6 promotes cell growth but its paracrine activity is required for the execution of oncogene-induced senescence (20). The PTTG protein, initially isolated from pituitary tumor cells, is a mammalian securin which facilitates sister-chromatid separation during metaphase. PTTG exhibits oncogene properties as its overexpression promotes cell malignant transformation and tumor formation (21). PTTG deletion results in pituitary cell senescence. However, high levels of PTTG may trigger oncogene-induced senescence (14).

In the present study, we detected the expression of the proteins involved in premature senescence pathways in normal, aging and tumorous pituitary gland tissues of rats. We successfully induced the aging pituitary gland using D-galactose (D-gal) injection as well as pituitary adenoma by chronic estrogen stress. Significant upregulation of IL-6, C/EBP $\beta$, p53, p21 and p16 expression as well as decreased expression of PTTG was observed in aging pituitary tissues. The expression of IL-6, p21 and p16 was decreased in the pituitary tumor gland compared with normal pituitary tissues, although there was no difference in the expression of p53 and $\mathrm{C} / \mathrm{EBP} \beta$ between the tumor and normal groups. Our data further confirm the senescence-associated gene expression reported by others and reveal the relative expression of these genes in normal, aging and neoplasia pituitary glands.

\section{Materials and methods}

Animal model. Fischer 344 rats were randomly divided into three groups with each group consisting of 12 rats. Group A formed the control group, group B formed the aging group and group $\mathrm{C}$ formed the tumor group. The rats in group $\mathrm{C}$ received chronic estrogen treatment using subcutaneous silastic controlled-release tube implants filled with $10 \mathrm{mg}$ diethylstilbestrol (DES) as described by Lloyd (22). Silastic capsules filled with normal saline were implanted as controls in groups A and B. The rats in group B were treated with a daily intraperitoneal injection of $\mathrm{D}$-gal solution at a dose of $200 \mathrm{mg} / \mathrm{kg}$. The rats were sacrificed by decapitation after 8 weeks. Blood was collected for PRL and IL-6 assays. The weights of the pituitary and body were recorded and analyzed. The standards of housing and care for laboratory animals conformed to the standards in the NIH Guidelines for the Care and Use of Animals. The experiments were approved by the Ethics Committee of Soochow University, China.

Immunohistochemistry. Pituitary tissues from the 12 animals in each group were fixed in Bouin's fluid and embedded in paraffin. PRL expression in pituitary tissue was determined using mouse monoclonal PRL antibody (murine; Dako, Carpinteria, CA, USA). The sections were immunostained and then incubated for $2 \mathrm{~h}$ at room temperature with anti-PRL primary antiserum, diluted 1:300. The sections were then treated for $30 \mathrm{~min}$ with a ready-to-use EnVision reaction system (Dako). The peroxide-sensitive chromogen was diaminobenzidine. Digital images were acquired from the light microscope (Olympus BX50, Japan) at x200 magnification via a CCD color camera (DS-Fi1; Nikon, Japan) and analyzed using a computer system (NIS-Elements F 3.0; Nikon).

SA- $\beta$-Gal staining. SA- $\beta$-Gal enzymatic activity was detected using a staining kit (Genmed Scientifics, Shanghai, China). Briefly, pituitary tissue samples were snap-frozen at optimal cutting temperature. Specimens were sliced in $10-\mu \mathrm{m}$ sections and dried for $1 \mathrm{~h}$ at room temperature. The sections were fixed and stained according to the instruction of manufacturer. The sections were then visualized by microscopy (Leica, Solms, Germany).

Enzyme-linked immunosorbent assay (ELISA). ELISA kits for rat PRL (code no. CSB-E06881r) and IL-6 (code no. CSB-E04640r) were purchased from Cusabio Company (Cusabio, Wuhan, China). Plasma was anticoagulated by EDTA and then centrifuged for $15 \mathrm{~min}$ at $1,000 \mathrm{x} \mathrm{g}$. The assay was performed according to the manufacturer's instructions.

$R N A$ extraction and quantitative polymerase chain reaction $(q P C R)$. Total RNA was extracted using TRIzol reagent (Invitrogen, Paisley, UK) according to the manufacturer's instructions. cDNA was synthesized using random primers (Takara, Dalian, China) with Moloney murine leukemia virus reverse transcriptase (Promega, Madison, WI, USA) at $37^{\circ} \mathrm{C}$ for $1 \mathrm{~h}$. For qPCR, the specific oligonucleotide primers were as follows: p53, 5'-GCTGAGTATCTGGACGACAGG-3' and 5'-AGCGTGATGATGGTAAGGATG-3'; p21, 5'-AGGGCT TTCTTTGTGTATTTGC-3' and 5'-GCCTGTTTCGTGTCT ACTGTTC-3'; p16, 5'-GGGCTTCCTAGACACTCTGGTA-3' and 5'-AGAAGTTATGCCTGTCGGTGAC-3'; C/EBP $\beta$, 5'-TTGTTGCTGTTGATGTTTTTGTT-3' and 5'-TCTTCA CTTTAATGCTCGAAACG-3'; PTTG, 5'-AAGGCTCTG GGAACTGTCAAC-3' and 5'-ATTTCTGGGTAGGCATCA TCAG-3'; IL-6, 5'-CACAAGTCCGGAGAGGAGAC-3' and 5'-ACAGTGCATCATCGCTGTTC-3'; and Rps16 which was used as the internal control, 5'-AAGTCTTCGGACGCAAGA AA-3' and 5'-TGCCCAGAAGCAGAACAG-3'. qPCR was performed in a $20 \mu \mathrm{l}$ reaction volume containing $2 \mu \mathrm{l} \mathrm{cDNA}$, $2 \mu \mathrm{l}$ primers, $6 \mu \mathrm{l}$ double-distilled $\mathrm{H}_{2} \mathrm{O}$ and $10 \mu \mathrm{l}$ SYBR-Green mix (Roche Molecular Biochemicals, Indianapolis, IN, USA). The PCR protocol consisted of 1 min denaturation at $95^{\circ} \mathrm{C}$, $30 \mathrm{sec}$ annealing of primers at $60^{\circ} \mathrm{C}$ and $30 \mathrm{sec}$ elongation at $72^{\circ} \mathrm{C}$, for a total of 30 cycles. Quantification of PCR was calculated as the difference between the cycle threshold $(\mathrm{Ct})$ value of the gene and the $\mathrm{Ct}$ value of the reference gene Rps16.

Statistic analysis. The values were presented as the means \pm SD. The results for the groups were compared using Student's t-test. $\mathrm{P}<0.05$ was considered to indicate a statistically significant difference.

\section{Results}

Effects of DES and D-gal treatment on the body and pituitary weight of rats. DES implantation and D-gal injection resulted in a slight decrease in the body weight of the rats in the aging and tumor groups compared with those in the control group (Fig. 1A). Correspondingly, slow response and dull fur were 
A

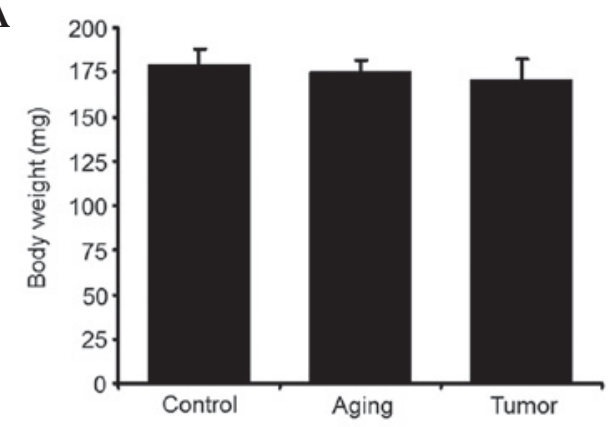

C

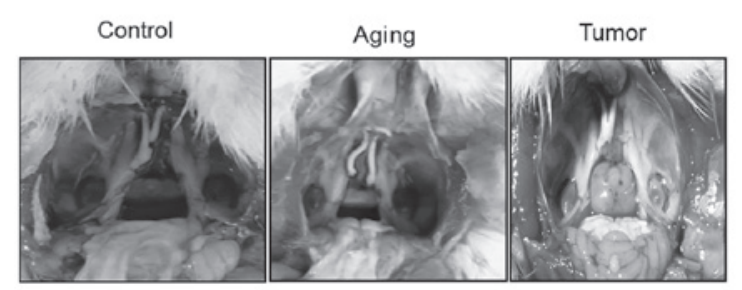

B

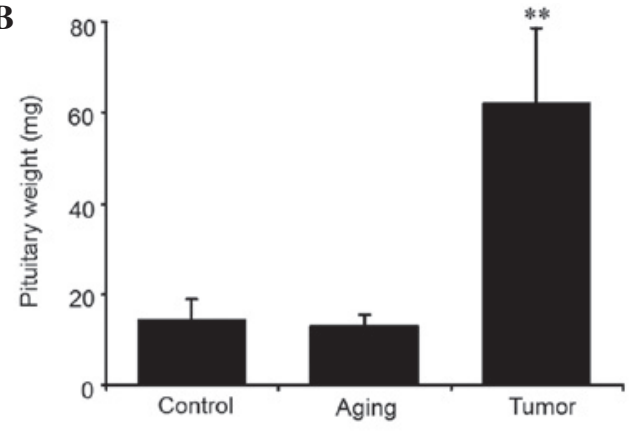

D

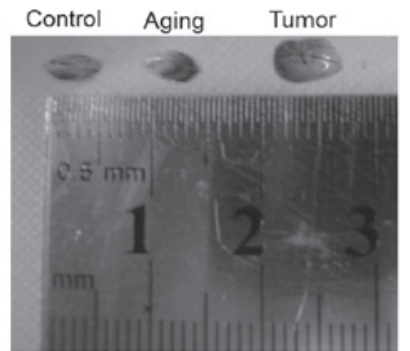

Figure 1. Effects of diethylstilbestrol (DES) and D-galactose (D-gal) treatment on the rat body and pituitary weight. (A) Body weights of Fischer 344 rats treated by DES and D-gal. The body weights were measured before the rats were sacrificed. Bars correspond to the means \pm SD. (B) Effects of DES and D-gal treatment on pituitary weight. Data are presented as the means \pm SD. ${ }^{* *} \mathrm{P}<0.01$ by two-tailed Student's t-test. (C) and (D) are representative images of the gross anatomy of pituitary glands.

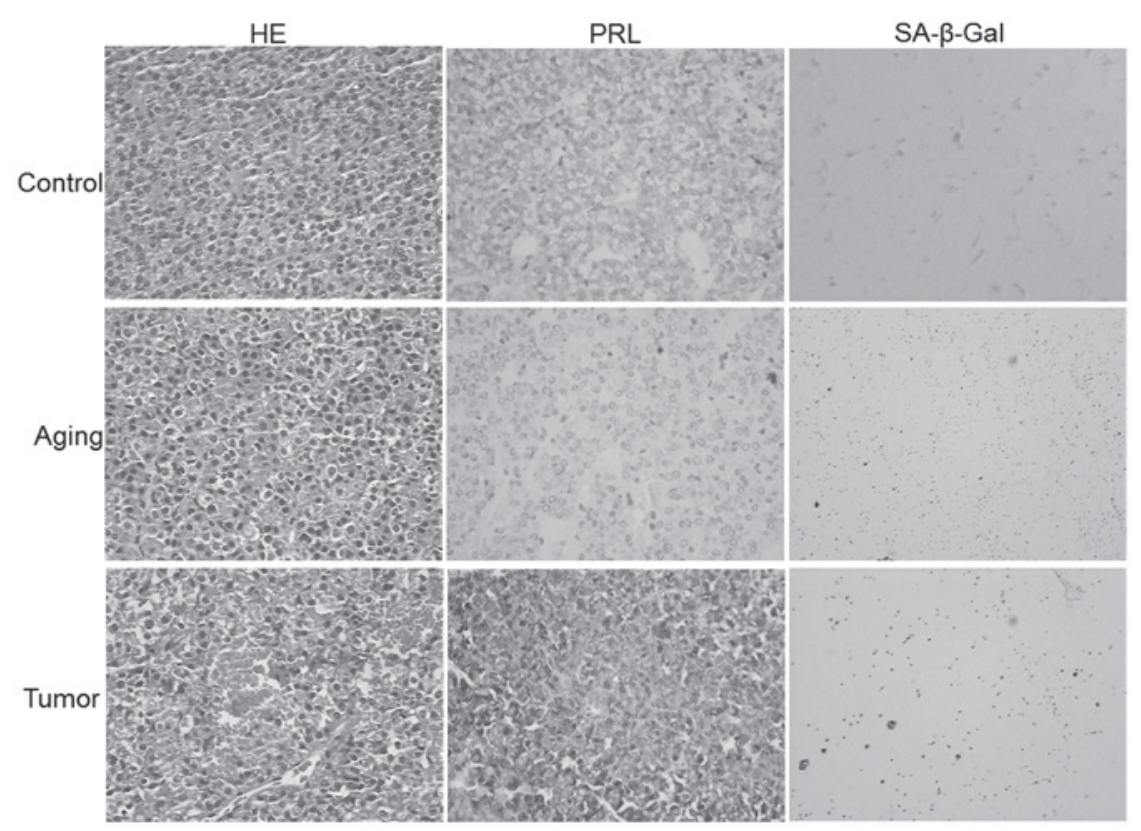

Figure 2. Histological staining of rat pituitary tissue sections. Left panel: hematoxylin and eosin (HE) staining; Middle panel: immunochemistry staining for prolactin (PRL). Positive cells were stained brown; Right panel: senescence-associated $\beta$-galactosidase (SA- $\beta$-Gal) staining. Positive cells staining was markedly increased in the Aging group. Tumor group showed $>90 \%$ strong positive PRL staining. Magnification, $\mathrm{x} 200$.

observed in the rats treated with D-gal, while the tumor group demonstrated a notable increase in the discharge of urine.

Compared with the control group, the pituitary weight was significantly increased in the tumor group which received the DES treatment $(\mathrm{P}<0.01$; Fig. 1B-D). In contrast, the pituitary weights of the aging group treated by $\mathrm{D}$-gal injection were almost the same as those of the control group (Fig. 1B-D).

Induction of prolactin-secreting pituitary tumor and aging rats. To further investigate whether DES implantation induced the pituitary tumor and D-gal treatment promoted pituitary aging, histological staining of the pituitary gland tissue was performed. Hematoxylin and eosin staining revealed hypertrophied cells with large nuclei and structural disorder in the tumor group receiving DES administration. Correspondingly, strong positive PRL staining was also observed in this group (Fig. 2). The plasma concentration of PRL was also detected using ELISA. The results revealed that the concentration of plasma PRL was significantly increased in DES-treated animals (Fig. 3A). D-gal treatment of the rats in the aging 

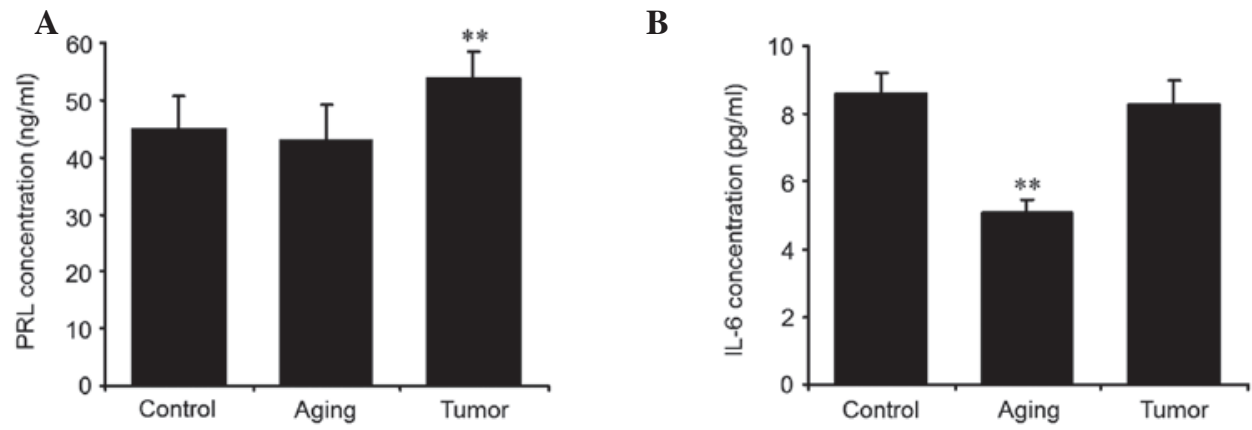

Figure 3. Plasma concentrations of prolactin (PRL) (A) and IL-6 (B). The data are presented as the means \pm SD. ${ }^{* *} \mathrm{P}<0.01$ by a two-tailed Student's t-test.

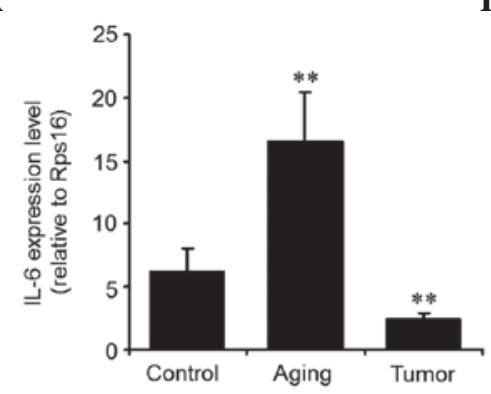

B

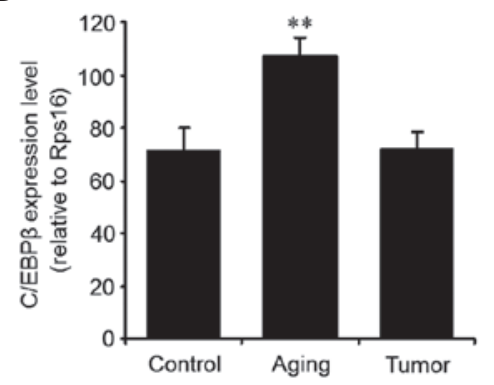

C

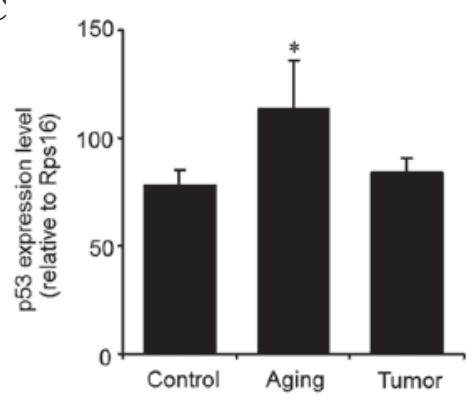

D

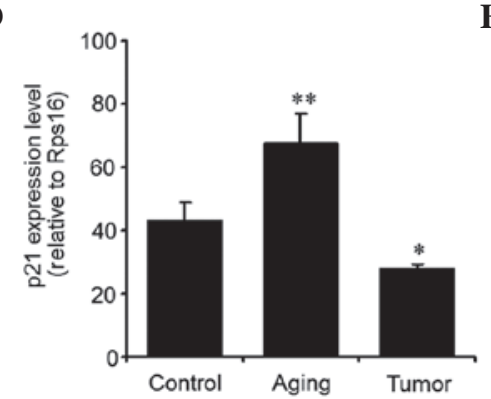

$\mathbf{E}$

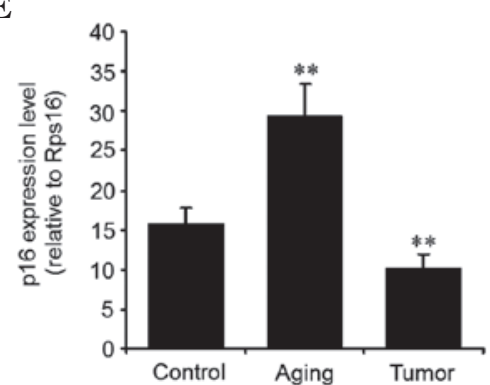

$\mathbf{F}$

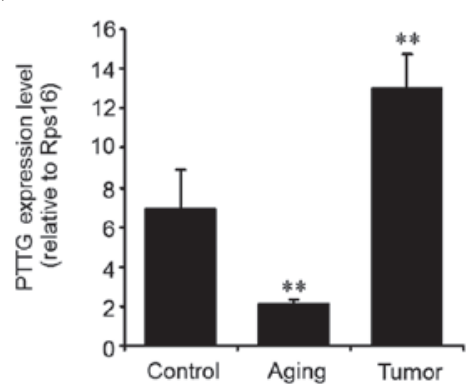

Figure 4. Expression of cellular senescence-related genes in normal, aging and neoplasia pituitary gland. Relative expression of IL-6 (A), C/EBP $\beta$ (B), p53 (C), p21 (D), p16 (E) and pituitary tumor transforming gene (PTTG) (F) was detected by quantitative polymerase chain reaction. Rps16 expression was used as an internal control. The bars indicate the means $\pm \mathrm{SD} ;{ }^{*} \mathrm{P}<0.05$ and ${ }^{* * *} \mathrm{P}<0.01$.

group resulted in strong senescence as evidenced by SA- $\beta$-Gal activity (Fig. 2). These results indicated that DES implantation successfully induced the PRL adenoma in the rat pituitary gland and that D-gal treatment promoted pituitary aging.

Gene expression associated with cellular senescence in aging and neoplasia pituitary gland. IL-6, one type of pleiotropic cytokine, exhibits either inhibitory or stimulatory effects in several pituitary tumors. IL-6 promotes pituitary proliferation in a paracrine manner and inhibits the growth of the pituitary in an autocrine manner. Plasma IL-6 was firstly detected using ELISA. The result revealed that plasma IL- 6 was lower in the aging group treated with D-gal than in the control group. There was no significant difference observed in the plasma IL-6 levels between the control and tumor group (Fig. 3B). The expression level of IL-6 in pituitary gland tissues was further detected using qPCR. The expression of IL- 6 was significantly increased in the aging group compared with the control group. A significant decrease in IL-6 expression was observed in the tumor group (Fig. 4A). The results indicated that IL-6 expression was increased in aging tissue but decreased in tumor tissue. Upregulation of IL-6 in aging tissue and downregulation of IL-6 in tumor tissue indicated that IL-6 expression was involved in the pituitary aging process and tumor genesis. However, endogenous IL-6 may underlie the slow proliferation rate and benign nature of pituitary tumors. It is plausible that paracrine IL-6 effects may allow initial pituitary cell growth, while autocrine IL-6 in the same tumor triggers senescence and restrains aggressive growth and malignant transformation.

The C/EBP $\beta$ transcription factor has been identified as a critical gene that regulates PRL expression and activates the expression of IL-6 (20). The expression of C/EBP $\beta$ in pituitary tissue was also detected. The results revealed that the expression of $\mathrm{C} / \mathrm{EBP} \beta$ was increased in the aging group compared with the control group (Fig. 4B).

The Cdk inhibitor $\mathrm{p} 21$, as a major mediator of cellular senescence, is one of the main targets of p53 for the induction of cell cycle arrest in response to DNA damage. The qPCR assay 
revealed that both $\mathrm{p} 53$ and $\mathrm{p} 21$ expression were significantly increased in the aging group. A notable decrease in p21 expression was observed in the tumor group (Fig. 4C and D). These results indicated that $\mathrm{D}$-gal treatment activated the expression of p53 and p21 which in turn contributed to the senescence of pituitary tissue. Thus, D-gal may successfully induce F344 rate to generate subacute senescent PRL adenoma.

The Cdk inhibitor p16 was also detected in pituitary tissues. The expression of p16 was significantly increased in aging pituitary tissue but was decreased in the pituitary tumor (Fig. 4E). Oncogene-induced senescence is enabled via the $\mathrm{p} 16 / \mathrm{Rb}$ or IL6/C/EBP $\beta$ senescence pathways. Our data also suggest that the expression of p16 induces an age-dependent decrease in the proliferative activity of pituitary cells and unipotent progenitors.

The PTTG protein, initially isolated from pituitary tumor cells, is abundantly expressed in pituitary tumors and exhibits oncogene properties. The results revealed that the expression of PTTG significantly decreased in the aging pituitary and notably increased in pituitary tumors (Fig. 4F).

\section{Discussion}

In the present study we demonstrated that the oncogene-induced senescence pathway IL-6/C/EBP $\beta$ and DNA damage pathway p53/p21 as well as p16 were activated in the aging pituitary gland treated by continuous injection of D-gal. No significant activation of these pathways was observed in the pituitary tumor induced by the DES implants. Pituitary tumor tissue exhibited low expression of p21 and p16, both of which are cell cycle suppressors. PPTG was downregulated in aging pituitary but upregulated in pituitary tumors. Oncogene-induced senescence is often accompanied by the upregulation of the CDK inhibitors p16INK4A and $\mathrm{p} 21$, as well as by an increase in SA- $\beta$-Gal activity.

$\mathrm{D}$-gal, a reducing sugar, is normally present in the body and is metabolized at normal concentration. When excessive D-gal is exposed to an organism, it may be oxidized into aldehydes and hydrogen peroxide, resulting in the accumulation of superoxide anion and oxygen-derived free radicals $(23,24)$. This oxidative stress disturbs the mitochondrial function, destroys cell structures and collapses the antioxidant mechanisms. Oxidative stress and reactive oxygen species are the major causes of aging (25). In the present study, we have successfully induced the pituitary aging model using D-gal treatment. Multiple cellular senescence pathways were activated under oxidative stress caused by D-gal administration, including the IL-6/C/EBP $\beta$, p53/p21 and p16 pathways.

Continuous treatment of Fischer 344 rats with estrogen results in the development of prolactin-secreting pituitary tumors, which provides a well-defined animal model for studying the pituitary adenomas (26). Commonly encountered, pituitary adenomas are invariably benign and grow slowly. Premature senescence is considered to be a significant mechanism in this indolent growth $(14,15)$. In the present study we detected the expression of the proteins involved in premature senescence-related pathways in pituitary tumors induced by DES implants. The results demonstrated that the expression of p53 and $\mathrm{C} / \mathrm{EBP} \beta$ in pituitary tumors was almost the same as that in the normal pituitary gland. As essential tumor suppressors, the normal expression of $\mathrm{p} 53$ and $\mathrm{C} / \mathrm{EBP} \beta$ may contribute to the limited proliferation of pituitary tumors.
An increasing amount of evidence demonstrates that cytokines play a significant role in the regulation of pituitary physiology and that oncogene-induced senescence is linked specifically to the activation of an inflammatory transcriptome. The cytokine IL-6 has received special attention due to its distinctive biological function. IL-6, detected in numerous cell types, demonstrates roles in various biological processes including immunity, inflammation, cancer and the aging process $(20,27)$. It has been reported that anterior pituitary cells express IL-6 (28). The production of IL-6 in pituitary cells may be regulated by a number of compounds, including IL-1 (28), estrogen (29) and glucocorticoids (30). IL-6 promotes pituitary tumor growth but inhibits the proliferation of normal pituitary cells (31). Our results revealed that IL-6 expression was significantly upregulated in aging pituitary tissue. This is consistent with a previous study which revealed that IL-6 expression is accumulated in senescence cells (20). These authors demonstrated that IL-6 mediated oncogene-induced senescence in a cell-autonomous mode. Its depletion caused the inflammatory network to collapse and abolished senescence entry and maintenance. The expression of IL- 6 is activated by $\mathrm{C} / \mathrm{EBP} \beta$, and the results suggest that $\mathrm{C} / \mathrm{EBP} \beta$ and IL- 6 constitute a positive feedback network regulating oncogene-induced senescence, and that $\mathrm{C} / \mathrm{EBP} \beta$ cooperates with IL-6 to amplify the activation of the inflammatory network (20). The expression of $\mathrm{C} / \mathrm{EBP} \beta$ was also increased in the aging pituitary. However, the plasma IL-6 concentration was decreased in aging rats compared with normal rats. This indicated that the paracrine activity of IL- 6 was inhibited in aging rats.

In the present study, the results revealed that the expression of IL-6, C/EBP $\beta$, p53, p21 and p16 was significantly increased in aging pituitary tissues. Downregulation of IL-6, p21 and p16 was observed in pituitary tumors compared with normal pituitary tissues. There was no significant change in the expression of p53 and C/EBP $\beta$ in pituitary tumor cells compared with normal ones. The expression of PTTG decreased in aging pituitary tissues but increased in pituitary tumors. In conclusion, our findings on the role of IL-6 in oncogene-induced senescence suggest the involvement of endogenous IL-6 in the development of the pituitary adenoma, and that pituitary cell growth regulation by IL- 6 underlies the role of cytokines as factors controlling pituitary cell division. IL-6 in the same tumor triggers senescence and restrains aggressive growth and malignant transformation. Further experiments are required to assess the use of this pathway as a target for effective therapy for tumor silencing and prevention of adenoma progression towards malignancy.

\section{Acknowledgements}

This study was supported by Plans for Graduate Research and Innovation in Colleges and Universities of Jiangsu Province (cxzz12-0839) and the Science Foundation for Young Scholars of Heilongjiang Province (QC2008C99).

\section{References}

1. Kovacs K, Horvath E and Vidal S: Classification of pituitary adenomas. J Neurooncol 54: 121-127, 2001.

2. Melmed S: Mechanisms for pituitary tumorigenesis: the plastic pituitary. J Clin Invest 112: 1603-1618, 2003. 
3. Ezzat S and Asa SL: Mechanisms of disease: The pathogenesis of pituitary tumors. Nat Clin Pract Endocrinol Metab 2: 220-230, 2006.

4. Levy A and Lightman S: Molecular defects in the pathogenesis of pituitary tumours. Front Neuroendocrinol 24: 94-127, 2003.

5. Melmed S: Pathogenesis of pituitary tumors. Nat Rev Endocrinol 7: 257-266, 2011.

6. Wierinckx A, Raverot G, Nazaret N, Jouanneau E, Auger C, Lachuer J, et al: Proliferation markers of human pituitary tumors: contribution of a genome-wide transcriptome approach. Mol Cell Endocrinol 326: 30-39, 2010

7. Scheithauer BW, Gaffey TA, Lloyd RV, Sebo TJ, Kovacs KT, Horvath E, et al: Pathobiology of pituitary adenomas and carcinomas. Neurosurgery 59: 341-353, 2006.

8. Arzt E, Chesnokova V, Stalla GK and Melmed S: Pituitary adenoma growth: a model for cellular senescence and cytokine action. Cell Cycle 8: 677-678, 2009.

9. Herbig U, Jobling WA, Chen BP, Chen DJ and Sedivy JM: Telomere shortening triggers senescence of human cells through a pathway involving ATM, p53, and p21(CIP1), but not p16(INK4a). Mol Cell 14: 501-513, 2004.

10. d'Adda di Fagagna F, Reaper PM, Clay-Farrace L, Fiegler H, Carr P, Von Zglinicki T, et al: A DNA damage checkpoint response in telomere-initiated senescence. Nature 426: 194-198, 2003.

11. Takai H, Smogorzewska A and de Lange T: DNA damage foci at dysfunctional telomeres. Curr Biol 13: 1549-1556, 2003.

12. Serrano M and Blasco MA: Putting the stress on senescence Curr Opin Cell Biol 13: 748-753, 2001.

13. Chesnokova V, Zonis S, Rubinek T, Yu R, Ben-Shlomo A Kovacs K, et al: Senescence mediates pituitary hypoplasia and restrains pituitary tumor growth. Cancer Res 67: 10564-10572, 2007.

14. Chesnokova V,Zonis S, Kovacs K, Ben-Shlomo A, Wawrowsky K, Bannykh S, et al: p21(Cip1) restrains pituitary tumor growth. Proc Natl Acad Sci USA 105: 17498-17503, 2008.

15. Chesnokova V, Zhou C, Ben-Shlomo A, Zonis S, Tani Y, Ren SG, et al: Growth hormone is a cellular senescence target in pituitary and nonpituitary cells. Proc Natl Acad Sci USA 110 E3331-E3339.

16. Collado M, Gil J, Efeyan A, Guerra C, Schuhmacher AJ, Barradas M, et al: Tumour biology: senescence in premalignant tumours. Nature 436: 642, 2005.

17. Mooi WJ and Peeper DS: Oncogene-induced cell senescence-halting on the road to cancer. N Engl J Med 355: 1037-1046, 2006.
18. Kuilman T and Peeper DS: Senescence-messaging secretome: SMS-ing cellular stress. Nat Rev Cancer 9: 81-94, 2009.

19. Collado M, Blasco MA and Serrano M: Cellular senescence in cancer and aging. Cell 130: 223-233, 2007.

20. Kuilman T, Michaloglou C, Vredeveld LC, Douma S, van Doorn R, Desmet CJ, et al: Oncogene-induced senescence relayed by an interleukin-dependent inflammatory network. Cell 133: 1019-1031, 2008.

21. Abbud RA, Takumi I, Barker EM, Ren SG, Chen DY, Wawrowsky K, et al: Early multipotential pituitary focal hyperplasia in the alpha-subunit of glycoprotein hormone-driven pituitary tumor-transforming gene transgenic mice. Mol Endocrinol 19: 1383-1391, 2005.

22. Lloyd RV: Estrogen-induced hyperplasia and neoplasia in the rat anterior pituitary gland. An immunohistochemical study. Am J Pathol 113: 198-206, 1983.

23. Lu J, Zheng YL, Luo L, Wu DM, Sun DX and Feng YJ: Quercetin reverses D-galactose induced neurotoxicity in mouse brain. Behav Brain Res 171: 251-260, 2006.

24. Wu DM, Lu J, Zheng YL, Zhou Z, Shan Q and Ma DF: Purple sweet potato color repairs d-galactose-induced spatial learning and memory impairment by regulating the expression of synaptic proteins. Neurobiol Learn Mem 90: 19-27, 2008.

25. Olanow CW: A radical hypothesis for neurodegeneration. Trends Neurosci 16: 439-444, 1993.

26. Spady TJ, McComb RD and Shull JD: Estrogen action in the regulation of cell proliferation, cell survival, and tumorigenesis in the rat anterior pituitary gland. Endocrine 11: 217-233, 1999.

27. Naugler WE and Karin M: The wolf in sheep's clothing: the role of interleukin- 6 in immunity, inflammation and cancer. Trends Mol Med 14: 109-119, 2008.

28. Spangelo BL, Judd AM, Isakson PC and MacLeod RM: Interleukin-1 stimulates interleukin-6 release from rat anterior pituitary cells in vitro. Endocrinology 128: 2685-2692, 1991.

29. Nagashima AC, Giacomini D, Castro CP, Pereda MP, Renner U, Stalla GK, et al: Transcriptional regulation of interleukin-6 in pituitary folliculo-stellate TtT/GF cells. Mol Cell Endocrinol 201: 47-56, 2003.

30. Schöbitz B, Van Den Dobbelsteen M, Holsboer F, Sutanto W and De Kloet ER: Regulation of interleukin 6 gene expression in rat. Endocrinology 132: 1569-1576, 1993.

31. Arzt E, Buric R, Stelzer G, Stalla J, Sauer J, Renner U, et al: Interleukin involvement in anterior pituitary cell growth regulation: effects of IL-2 and IL-6. Endocrinology 132: 459-467, 1993. 